\title{
Acceptance of The Kangaroo Care Method by Mothers in Rural Area
}

\author{
Rulina Suradi, Imral Chair, Ridwan M. Thaha
}

\begin{abstract}
We evaluate the acceptance of Kangaroo Care Method (KCM) among rural mothers giving birth to LBW infants in the rural health centers of 3 provinces in Indonesia, from June 1 through November 30, 1997. All mothers giving birth to LBW infants (birth weight 1500-2500 grams) seen by the rural team on the first clay with no morbidity requiring hospitalisation were included in this study. One hundred and sixteen mothers fulfilled the criteria, most of them (62.1\%) were between 20-29 years of age. Birthweight between 2000-2500 grams was found in $86.2 \%$ of infants, and $67.3 \%$ are fullterm small for date babies. Most respondents accepted the KCM because they were interested in a new and practical method showed by the midwife; $11.8 \%$ accepted it because it resembled the local habit. All the mothers in the three locations had a positive perception on the benefit of KCM; 90\% found that their babies were more calm, 92.7\% said that their babies slept more and $85.4 \%$ said that their babies breastfed more often. As for their feelings, everyone said that they felt happy. As many as $86.4 \%$ of mothers practiced the use of KCM during the 28 days, but only $40 \%$ of them used them for a total of more than 5 hours a day. More than $80 \%$ of the mothers had support from the family and more than $60 \%$ had a substitute for the KCM. We conclude that KCM was feasible and acceptable among the rural community. [Paediatr Indones 1998; 38:215-223]
\end{abstract}

\section{Introduction}

Indonesia with a population of more than 200 million people persently has a population increase of about 5 million a year, of which 70 percent are born outside the health facilities. The infant mortality rate reported in 1994 was 58 per 1000 live births. This figure is higher in the rural area compared to in the urban area and differs from province to province. ${ }^{1}$ Forty percent of the infant mortality occurs in the neonatal period of which $42.3 \%$ were due to perinatal causes and its highest contributor was low birth

Author's address: Dr. Rulina Suradi, Department of Child Health, Medical School, University of Indonesia, Jakarta, Jalan

Salemba 6, Jakarta 10430. Indonesia. Tel 62-21-3155742, Fax 3907743 
weight (LBW). ${ }^{2}$ The prevalence of LBW infants ranges from $13-17 \%{ }^{3}$ and the morbidity and mortality are still high. One of the causes of morbidity and mortality among LBW infants is hypothermia. ${ }^{+}$

The skin-to-skin contact or Kangaroo Care Method (KCM) describes the prctice of holding a preterm infant naked (except for a diaper) between the mother's breast in an upward position. Since the introduction of this method by Rey and Martinez in Bogota, Colombia in 1970, several studies also in Indonesia have proven that this method is an appropriate and effective technology in caring for the preterm and LBW infants to prevent hypothermia. This method is thus recommended to use in rural areas where facilities like incubators are still aluxury and the referral system is not yet working well. ${ }^{49}$ Not many of those studies specifically look for the acceptance of the mothers for this new method of caring for the LBW infants. As a new thing the acceptance of this method depends on the motivation of the people to adopt and this depends on the strategy of communication by the health providers. ${ }^{10}$ In general this study aimed to assess the acceptance of KCM among rural mothers giving birth to LBW infants. Specifically, this program aimed to increase knowledge and acceptance of $\mathrm{KCM}$ among health professionals, to provide information and motivation to mothers having LBW infants, to identify reasons for acceptance or refusal of KCM, to assess the perception, attitude and practice of respondents including the support from other members of the family to KCM, and to evaluate body-temperature and body-weight of babies during KCM.

\section{Methods}

This study is an operational interventional study on mothers giving birth to LBW infants. The area of study included South Sumatra Province (District Ogan Komering Ulu, 4 health centers), North Sumatra Province (Deli Serdang District, 4 health centers), and South Sulawesi Province (Maros District, 4 health centers). The study was conducted from June 1, through November 30, 1997.

All mothers giving birth to LBW infants (birth weight 1500-2500 grams seen by the rural team on the first day, and the infants showed no morbidity requiring hospitalization and had a good sucking reflex were included in this study. Mother's consent was obtained from all study subjects.

The activities follow the following steps: Preparation of materials like forms, guidelines and modules was developed. Seminar in 3 provinces for the officials of the municipal health. Training in KCM and communication, levelwise, training for trainers in Jakarta, training for district team in the capital of the province, and training for rural team in the district capital. The next step was identification and recording of possible sample population ( $>26$ weeks pregnant mothers), followed by reporting of births with birthweight between 1500-2500 grams to the rural team. The rural team then 
provided motivation to mothers to practice KCM. Visits to mothers with LBW infants were done. For those who accepted KCM visits were done 10 times, i.e. on days $1,2,3$, $4,5,6,9,14,20,28$ with interview on days 6 and 28. For those who refused KCM, visits were done 5 times, i. e. on days $1,6,14,20,28$ with interview on day 6 . During each visit body temperature and body weight were obtained at approximately the same time every visit. Supervision was conducted by principal investigators with the local team to area of study. The evaluation of the whole study was performed by data analysis and focus group discussion.

\section{Results and Discussion}

\section{Sample characteristics}

From the 16 health centers during the time of study, 116 mothers fulfilled the criteria, 82 from District Ogan Komering Ulu (OKU), 22 from Deli Serdang, and 12 from Maros. From the 116 mothers only six refused to use the KCM as a way of caring for their infants; all of them were from district OKU. The length of study was shorter in district Deli Serdang and Maros compared to district OKU, so that fewer mothers could be included in the study. Most of the mothers (62.1\%) were between 20-29 years of age. The infants' birth weight was between $2000-2500$ grams, comprised $86.2 \%$ and $67.3 \%$ were full-term small for date babies. There were three babies with birth weight of less than 1500 grams which was not in the criteria of inclusion but because the mothers refused their babies to be referred and because the babies were small for date and the sucking reflex was good they were included in the study. (See Tables 1 and 2).

We only included babies with birth weight of more than 1500 grams with no morbidity, had a good sucing reflex. This was unlike Rey and Martinez study which included babies of 1000 grams, because we wanted to be sure that nothing bad would happen to the baby as our interest is the acceptence of the mother of KCM.

Table 1. Distribution of respondents by age of mother

\begin{tabular}{lrcrrc}
\hline Mother's age (years) & OKU & Deli Serdang & Maros & Total & $\%$ \\
\hline$<20$ & 8 & 3 & 3 & 14 & 12.1 \\
$20-29$ & 52 & 16 & 4 & 72 & 12.1 \\
$30-39$ & 20 & 3 & 5 & 28 & 24.1 \\
$>40$ & 2 & 0 & 0 & 2 & 1.7 \\
\hline
\end{tabular}




\section{Birth attendant}

More than $75 \%$ of births were helped by skilled birth attendants. Yet in some emergency cases births were helped by untrained birth attendants, but were reported within 24 hours to the team so that they were included in the sample. See Table 3.

Table 2. Distribution of respondents according to birth-weight and gestational age

\begin{tabular}{crrrrc}
\hline & OKU & Deli & Maros & Total & $\%$ \\
\hline Birthweight (grams) & 0 & 3 & 0 & 3 & 2.5 \\
- 1500-2000 & 6 & 5 & 2 & 13 & 11.3 \\
- 2001-2500 & 76 & 14 & 10 & 100 & 86.2 \\
Gestational age & & & & & \\
" <36 weeks & 30 & 6 & 2 & 38 & 32.7 \\
" 37 weeks & 52 & 16 & 10 & 78 & 67.3 \\
\hline
\end{tabular}

Table 3. Distribution of respondents according to birth attendant

\begin{tabular}{lrrrrr}
\hline \multicolumn{1}{c}{ Birth attendant } & OKU & Deli Serdang & Maros & Total & $\%$ \\
\hline Physician & 5 & 1 & 0 & 6 & 5.2 \\
Health center widwife & 16 & 1 & 1 & 18 & 15.6 \\
Community midwife & 47 & 8 & 8 & 63 & 54.3 \\
Trained TBA & 10 & 12 & 3 & 25 & 21.5 \\
Untrained TBA & 4 & 0 & 0 & 4 & 3.4 \\
\hline
\end{tabular}

\section{Acceptance of KCM}

Most of the respondents accepted the KCM because they listened to what the midwife asked them to do because they believed that the midwife knew better, and they were interested in a new and practical method showed by the midwife. And a part of them $11.8 \%$ accepted it because it resembled the local habit, i.e. 'bedako' in OKU and 'makalepe' in the Makassar language and 'kaclukui' in the Bugis language, both 
languages are spoken in District Maros. On the contrary in district Deli Serdang there was no traditional method resembling the KCM. See Table 4. For mothers who refused to try the KCM (only in OKU district), 50\% of them gave the reason because they were afraid of the baby's condition (Table 5).

Table 4. Distribution of respondents by reason of acceptance

\begin{tabular}{|c|c|c|c|c|c|}
\hline Reasons to acceptance & OKU & Deli Serdang & Maros & Total & $\%$ \\
\hline $\begin{array}{l}\text { Don't know what else to do } \\
\text { (baby too small) }\end{array}$ & 12 & 9 & 2 & 23 & 20.9 \\
\hline $\begin{array}{l}\text { Interested in a new and prac- } \\
\text { tical method }\end{array}$ & 57 & 13 & 4 & 74 & 67.3 \\
\hline Resembling local habit & 7 & 0 & 6 & 13 & 11.8 \\
\hline
\end{tabular}

Table 5. Distribution of respondents by reasons of refusal (only in OKU)

\begin{tabular}{ll}
\hline \multicolumn{1}{c}{ Reason of refusal } & $\mathrm{n}$ \\
\hline $\begin{array}{l}\text { Afraid for the baby (will fall, } \\
\text { can not breath) }\end{array}$ & 3 \\
$\begin{array}{l}\text { Mother sick, afraid baby } \\
\text { contaminated }\end{array}$ & 1 \\
\begin{tabular}{l} 
Not practical \\
\multicolumn{1}{c}{ Total }
\end{tabular} & 2 \\
\hline
\end{tabular}

\section{Perception and feelings towards KCM}

The information on perception and attitude was perceived from the interview on days 6 and 28 taken from mothers who accepted the KCM. All the mothers in the three locations had a positive perception on the benefit of $\mathrm{KCM}, 90 \%$ found that their babies were more calm, $92.7 \%$ said that their babies slept more, and $85.4 \%$ said that their babies breastfed more often (see Table 6). As for their feelings, everyone said that they felt happy, $30.9 \%$ of them felt ticklish, $20 \%$ felt awkward and $10 \%$ felt shy. One mother felt very proud and showed of the use of KCM to her neighbors from her balcony, because there was a believe that babies less than 40 days are not allowed to go outside the house. See Table 7. 
In Sweden Alfonso and colleagues conducted an explorative study of mothers reaction to the $\mathrm{KCM}$. The $\mathrm{KC}<\mathrm{M}$ mothers appeared more satisfied and optimistic, they had more confidence in their own ability and the strength of the child. ${ }^{11}$

\section{Practice in using the KCM}

By practice we meant the actual use of KCM that is how many days during the study, how many hours a day, what position they use and whether during the use of KCM the mother could still do other household jobs. As many as $86.4 \%$ of mothers practiced the use of KCM during the 28 days, but only $40 \%$ of them used them for a total of more than 5 hours a day (see Table 8). The upright position (standing or sitting position) was preferred to the lying down position (52.7\% vs $15.5 \%$ ) while $31.8 \%$ used both positions (see Table 9). Only 35\% of mothers were not afraid to do other work during practicing the KCM. See Table 10.

A study by Whitelaw and colleagues in London ${ }^{9}$ proved that the duration of using the KCM method for as short as 36 minutes a day already showed a difference in the mean duration of breastfeeding ( 9.2 weeks in $\mathrm{KCM}$ vs. 5.1 weeks in the control group).

Table 6. Distribution of respondents by perception

\begin{tabular}{lrrrrc}
\hline \multicolumn{1}{c}{ Perception } & OKU & Deli Serdang & Maros & \multicolumn{1}{c}{$\mathrm{n}$} & $\%$ \\
\hline Baby more calm & 73 & 17 & 9 & 99 & 90.0 \\
Baby sleep more & 71 & 21 & 10 & 102 & 92.7 \\
Baby stays warm & 67 & 7 & 4 & 78 & 70.9 \\
$\begin{array}{l}\text { Baby breastfeeds } \\
\text { more often }\end{array}$ & 63 & 19 & 12 & 94 & 85.4 \\
\hline
\end{tabular}

Table 7. Distribution of respondents according to their feelings

\begin{tabular}{lrcccc}
\hline \multicolumn{1}{c}{ Feeling } & OKU & Deli Serdang & Maros & Total & $\%$ \\
\hline Happy & 78 & 22 & 12 & 110 & 100.0 \\
Ticlish & 23 & 8 & 3 & 34 & 30.9 \\
Awkwrad & 8 & 9 & 5 & 22 & 20.0 \\
Shy & 3 & 5 & 3 & 11 & 10.0 \\
\hline
\end{tabular}




\section{Family support}

From the study we found that more than $80 \%$ of the mothers had support from the family and more than $60 \%$ had a substitute for the KCM. (see Tables 11 and 12).

\section{Body temperature and weight gain}

Some babies had low body temperature when first seen by the local team, but after the use of KCM the temperature rose to normal. During the study, not any case of hypothermia occurred in the newborns after the use of the KCM and weight gain is also acceptable (data is reported elsewhere).

Table 8. Duration of KCM

\begin{tabular}{lrcrrc}
\hline & OKU & Deli Serdang & Maros & Total & $\%$ \\
\hline During study & 64 & 20 & 11 & 97 & 86.4 \\
* until 28 days & 12 & 2 & 1 & 15 & 13.6 \\
- less than 28 days & 12 & 2 & 1 & 15 & 13.6 \\
Per day & & & & & \\
- more than 5 hours & 25 & 12 & 7 & 44 & 40.0 \\
- less than 5 hours & 51 & 10 & 5 & 66 & 60.0 \\
\hline
\end{tabular}

Table 9. Position during KCM

\begin{tabular}{lrcccc}
\hline \multicolumn{1}{c}{ Position } & OKU & Deli Serdang & Maros & Total & $\%$ \\
\hline Upright & 44 & 9 & 5 & 58 & 52.7 \\
Lying down & 3 & 10 & 4 & 17 & 15.5 \\
Both & 29 & 3 & 3 & 35 & 31.8 \\
\hline
\end{tabular}

Table 10. Doing other work during KCM

\begin{tabular}{lccccc}
\hline \multicolumn{1}{c}{ Doing other work } & OKU & Deli Serdang & Maros & Total & $\%$ \\
\hline Yes (cooking, cleaning, etc) & 19 & 13 & 7 & 39 & 35 \\
No & 57 & 9 & 5 & 71 & 65 \\
\hline
\end{tabular}


222 Acceptance of Kangaroo Method in rural area

Table 11. Family support

\begin{tabular}{crrrrc}
\hline Family support & OKU & Deli Serdang & Maros & Total & $\%$ \\
\hline - Positive & 59 & 20 & 10 & 89 & 80.9 \\
- Negartive & 17 & 2 & 2 & 21 & 19.1 \\
\hline
\end{tabular}

Table 12. Substitute for KCM from family

\begin{tabular}{lrcccc}
\hline \multicolumn{1}{c}{ Substitute } & OKU & Deli Serdang & Maros & Total & $\%$ \\
\hline Husband & 29 & 13 & 3 & 45 & 40.9 \\
Birthweight (grams) & 9 & 1 & 1 & 11 & 10.0 \\
Other family members & 6 & 2 & 3 & 11 & 10.0 \\
No substitude & 22 & 6 & 5 & 43 & 39.1 \\
\hline
\end{tabular}

\section{Conclusions and Recommendations}

KCM was feasible and acceptable among the rural community who had LBW babies in the study area and it was similar to the local habit in OKU and Maros District. The KCM proved to be an appropriate technology to prevent hypothermia and resulting in stabilization of body temperature during the critical newborn period. The community village midwifes and TBAs are potential change agents in communicating the implementation of the $\mathrm{KCM}$ among mothers with LBW infants in the village, provided that they were trained in good interpersonal communication and use appropriate adult teaching methods. Considering that Indonesia consists of different ethnics and local cultures, it is strongly recommended to design a similar intervention study to be conducted in other areas in Indonesia to find out the unique local terms and existing cultures which are conducive to the acceptance of the KCM to care for the LBW infants. This effort hopefully will significantly contribute to the reduction of mortality and morbidity due to hypothermia.

\section{Acknowledgments}

The authors are thankful to the Department of Health for finding the funds for the study, and to Prof. Anna Alisyahbana, Dr. Hadi Pratomo, Sari Handayani, Dr. Julniar Tasli, Dr Dachrul Aldy and Dr Djauhariah and the local teams for their participation in the study. 


\section{References}

1. Ministry of Health. The Indonesian health profile. Jakarta, 1994.

2. Ministry of Health. Prevention and management of hypothermia in low birth weight infants. Jakarta, 1995.

3. Alisyahbana, A. The implementation of the risk approach on pregnancy outcome by attendants. The Tanjungsari study in West Java, Indonesia. Dissertation, Erasmus University, Rotterdam, 1993.

4. Usman A, Irawaty S, Triyanti A.,et,al. Prevention of Hypothermia in Low Birth Weight Infants using the Kangaroo-Mother Care at Home. Bandung; Medical Research Unit, Padjadjaran University. 1996.

5. Surjono A, Ekawaty LH, Dwikisworo et.al. Kangaroo-Mother Care in Low Birth Weight Infants: A Randomized Controlled Trial. Yogyakarta: Department of Child Health Faculty of Medicine, Gajah Mada University. 1996.

6. Anderson GC. Current knowledge about skin-to-skin (kangaroo) care for preterm infants. J Perinatol 1991; 11:216-26.

7. Sloan NL, Leon Camacho LW, Pinto Rojas E, Stern C, and Maternidad Isidró Ayora Study Team: Kangaroo mother method: randomized controlled trial of an alternative method of care for stabilized low-birth weight infants. Lancet 1994; 344:782-5.

8. Collona F, Uxa F, Da Garca AM, De Vonderweld U. The "kangaroo-mother" method: evaluation of an alternative model for the care of low birthweight newborns in developing countries. Int j Gynecol Obstet 1990; 31:335-9.

9. Whitelaw A, Heisterkamp G, Sleath K, Acolet D, Ricard M. Skin to sikin contact for very low birthweight infants and their mothers. Arch Dis Childh 1988; 63:1377-81.

10. Helen R, Mico PR. Theory and Practice in Health Education. Fourth Edition, Mayfield Publishing Company. 1991.

11. Alfonso DD, Wahlberg V, Persson B. Exploration of mothers' reaction to the Kangaroo method of prematurity care. Neonatal Network 1989; 7:43-51. 